\title{
The New Pact: How Online Worlds Forge a New Form of Alliance between Players and Designers
}

\author{
Nicolas Gaume \\ Founder and CEO of Mimesis Republic
}

\begin{abstract}
Today's Pop Culture is tomorrow's classic. Entertainment is often able to reflect a society's questions and anxieties of the day. We will discuss how and why today's Digital Generation has replaced their grandparents' heroes and their parents' anti-heroes by their very own avatars. How and why the empathy with heroes that has traditionally been utilized by movies has been gradually overtaken by the personalized and immersive experience of games as lived through the eyes of an avatar? How multiplayer activities are now establishing new social paradigms where these avatars help us all deal with the natural schizophrenia of everyday life by allowing us to explore our possible selves. The Social Networks boom has demonstrated our appetite for connections with others; and games our appetite for second lives, our desire to involve ourselves and master complex worlds. Perhaps, tomorrow new public Agoras will be created from a new generation of Virtual Worlds built using the grammar that video games have forged over the last 40 years...
\end{abstract}

The Author. Nicolas Gaume founded in 1990, at the age of 19, Kalisto Entertainment, a video game development studio. Over its 12 years of life, Kalisto produced more than 50 titles for PC and consoles. Kalisto also worked with Orange to launch their mobile games efforts. The company employed a staff of over 350 people in the USA, Japan and France. Besides his Kalisto venture, Nicolas Gaume founded in 1994, NGM Productions, a children book publishing company in China. NGM published popular French series such as "Père Castor" (Flammarion) or "Les Incollables/Brain Quest" (Play Bac) between 1994 and 1999, when the company was sold. He also co-founded, in 1995, one of the first French web agency, Wcube, sold to Swedish group, Framfab, and, in 2000, a wine promotion site, winealley.com. He was also board member of the French media group Sud-Ouest, of the TV animation production company, Xilam \& of the German data management software publisher, NXN, sold in 2004 to Avid. Between July 2002 and May 2005, Nicolas has worked as a consultant advising media group such as AOL, Orange or Lagardère and game companies such as Codemasters or Ubisoft, primarily on their development \& partnerships strategies. For thee years, Nicolas Gaume was then Senior VP \& GM of the mobile games \& applications division of Cellfish Media, a Lagardère company. Early 2008, he founded a new company, Mimesis Republic, focusing on the design, development and operation of virtual worlds and social networks. He also currently serves as chairman of the French national video game development school -ENJMIN- and president of the French game developers association, SNJV. 